\title{
Depletion of Glial Cell Line-Derived Neurotrophic Factor by Disuse Muscle Atrophy Exacerbates the Degeneration of Alpha Motor Neurons in Caudal Regions Remote from the Spinal Cord Injury
}

\author{
Yu-Ichiro Ohnishi*, Koichi Iwatsuki, Toshiki Yoshimine \\ Department of Neurosurgery, Osaka University Medical School, Suita, Japan \\ Email: ohnishi@nsurg.med.osaka-u.ac.jp
}

Received 17 September 2014; revised 16 October 2014; accepted 12 November 2014

Copyright (C) 2014 by authors and Scientific Research Publishing Inc.

This work is licensed under the Creative Commons Attribution International License (CC BY).

http://creativecommons.org/licenses/by/4.0/

(c) (i)

\begin{abstract}
We have been previously reported that disuse muscle atrophy exacerbates both motor neuron (MN) degeneration in caudal regions remote from a spinal cord injury, and decrease in glial cell line-derived neurotrophic factor (GDNF) protein level in paralyzed muscle. In this study we found that disuse muscle atrophy exacerbated the decrease in GDNF protein level in the L4/5 spinal cord, which was not immunopositive for GDNF. Our results were consistent with the fact that in the lumbar spinal cord of rats with mid-thoracic contusion, GDNF expression was not detected, while expression of GDNF receptors (GFR $\alpha 1$ and RET) was. Our study showed that administration of exogenous recombinant GDNF into the atrophic muscle partially rescued $\alpha$-MN degeneration in the L4/5 spinal cord. These results suggest that the depletion of GDNF protein by muscle atrophy exacerbates $\alpha$-MN degeneration in caudal regions remote from the injury.
\end{abstract}

\section{Keywords}

Disuse Muscle Atrophy, Motor Neuron, Degeneration, Glial Cell Line-Derived Neurotrophic Factor

\section{Introduction}

Neurons derive trophic support from the muscles, which are a source of trophic factors (TFs) [1]. Glial cell

${ }^{*}$ Corresponding author.

How to cite this paper: Ohnishi, Y.-I., Iwatsuki, K. and Yoshimine, T. (2014) Depletion of Glial Cell Line-Derived Neurotrophic Factor by Disuse Muscle Atrophy Exacerbates the Degeneration of Alpha Motor Neurons in Caudal Regions Remote from the Spinal Cord Injury. Neuroscience \& Medicine, 5, 214-221. http://dx.doi.org/10.4236/nm.2014.55025 
line-derived neurotrophic factor (GDNF) is crucial to the survival of spinal motor neurons (MNs) [2]. TFs derived from the target muscle (by retrograde transport), from afferent neurons (by anterograde transport), from neighboring glial cells, or even via autocrine production, support the survival of spinal MNs [3]-[5].

Although normal muscle is a source of TFs for spinal MNs, there is a considerable decrease in TF levels in atrophic muscles, in part due to elevated levels of ubiquitin ligases and decreased protein synthesis [6]-[8]. It has been reported that limb immobilization produces atrophic muscles [6] [9]-[11]. On the other hand, training increases TFs including GDNF in skeletal muscle [12] [13]. The effects of TFs derived from muscle on the degeneration of spinal MNs have not yet been fully clarified. We hypothesize that disuse muscle atrophy decreases the availability of muscle-derived TFs available for retrograde transport.

We have previously reported that disuse muscle atrophy within the context of spinal cord injury exacerbates not only MN degeneration in caudal regions remote from the injury but also the decrease in GDNF protein level in paralyzed muscle [11]. In this study, disuse muscle atrophy was associated with a significant decrease in GDNF protein levels in the L4/5 spinal cord. Administration of exogenous recombinant GDNF into the atrophic muscle partially rescued $\alpha$-MN degeneration.

\section{Materials and Methods}

\subsection{Animals}

Six-week-old adult male Sprague-Dawley rats (n = 31; weight, 195 - 210 g; Japan SLC Inc., Hamamatsu, Japan) were randomly assigned to undergo laminectomy only (laminectomy, $n=4$ ), spinal cord injury only (injury, $n=$ 10 ), or spinal cord injury with hind limb immobilization (injury + immobilization, $n=17$ ). Histological study was performed for laminectomy $(n=2)$, injury $(n=6)$ and injury + immobilization $(n=6)$ group respectively. ELISA study was performed for laminectomy $(n=2)$, injury $(n=4)$ and injury + immobilization $(n=4)$ group respectively. Injection study was performed for injury + immobilization group (PBS injection, $n=3$; GDNF injection, $n=4)$. The laminectomy group was a control group in this study. The protocol was approved by the Animal Committee of Aino University, Japan. All procedures were performed in accordance with the Guidelines for Animal Experiments of Aino University and in compliance with the Japanese Regulations for Animal Welfare.

\subsection{Interventions}

Basic surgical procedures and postoperative care were as described previously [11] [14]-[16]. Laminectomy was performed at the mid-thoracic vertebrae 7/8. The spinal cord was crush-injured by dropping a 10-g metal rod from a height of $7.5 \mathrm{~cm}$ using a New York University (NYU) impactor [17]-[19].

After surgery, the right and left hind limbs were immobilized with aluminum plates on soft sponges, with the ankle and knee joints fully extended. The gastrocnemius and tibialis anterior muscles were immobilized in the contracted and extended positions, respectively. The quadriceps and hamstring muscles were immobilized, but rats could move their hind limbs at the hip joints.

Recombinant GDNF protein (R \& D Systems, Inc., Minneapolis, MN) or control phosphate-buffered saline (PBS) injection was administered to the injury + immobilization rats. GDNF at a concentration of $200 \mu \mathrm{g} / \mathrm{mL}$ or PBS alone was injected into the gastrocnemius muscles of both legs, using a 26G needle, at a depth of $1 \mathrm{~mm}$ and for a duration of 3 minutes; this was done twice weekly for 3 weeks following the crush injury. The gastrocnemius muscle was removed and, prior to transcardial paraformaldehyde perfusion, the wet weight was measured (PBS group, $n=3$; GDNF injection, $n=4$ ).

\subsection{Histological Evaluation}

The spinal cords of the rats were cut into 2-mm lengths from the lesion site to the lumbar enlargement and were embedded in optimal cutting temperature (OCT) compound (laminectomy, $n=2$; injury, $n=6$; injury + immobilization, $n=6$ ) (Tissue Tek, Sakura Finetechnical, Tokyo, Japan) at 3 weeks postintervention. The gastrocnemius muscle was removed prior to paraformaldehyde perfusion at 3 weeks postintervention. The muscles were then immediately frozen in acetone chilled with dry ice, and were embedded in OCT compound. Sections (thickness, $10 \mu \mathrm{m}$ ) were cut axially from the blocks by using a cryostat (CM1510S; Leica), and every fifth section was saved. A set of sections was mounted on 20 silane-coated glass slides (Matsunami, Tokyo, Japan) for 
each animal. Sections were used for hematoxylin and eosin (HE) staining and immunohistochemical analysis. The primary antibodies were anti-neuronal nuclei (NeuN) mouse polyclonal (1:100; Chemicon International, Inc., CA), anti-glial fibrillary acidic protein mouse monoclonal (1:300; Sigma, Tokyo, Japan) for astrocytes, and anti-GDNF goat polyclonal (1:10; R \& D, Minneapolis, USA). Secondary antibodies were cyanine 3 (Cy3)labeled anti-mouse IgG (1:1000; GE Healthcare Bio-Sciences Corp., NJ) and anti-goat Alexa Fluor 488 IgG (1:1000; Molecular Probes, OR).

\subsection{MN Counts}

The diameter of $\alpha$-MN in lumbar spinal cord distribute from 30 to $50 \mu \mathrm{m}$, and peak at $40 \mu \mathrm{m}$ [20]. Sections (thickness, $10 \mu \mathrm{m}$ ) were cut axially from the blocks by using a cryostat; every 5th section was saved. A set of sections was mounted on 20 silane-coated glass slides for each animal. Ten slides from 1 animal in each group were stained with anti-NeuN antibody, and the sections were examined by fluorescence microscopy (ECLIPSE E600, Nikon, Tokyo, Japan; DP71, Olympus, Tokyo, Japan). We scanned each section at 100× magnification, and counted the identified motor neurons at 40- $\mu \mathrm{m}$ intervals to prevent from biased counting. Mean $\alpha$-MN counts were calculated for each group using the counts from each animal. The number of large (diameter, $\geq 40 \mu \mathrm{m}$ ) cells containing a single nucleolus located in the ventral horn was recorded and measured on both sides of each section with the use of an image analysis software (ImageJ, version 1.44; http://rsbweb.nih.gov/ij/index.html) [21] [22].

\subsection{Cavity Measurement}

We examined the HE sections to measure cavity volume [14] [15]. Images were obtained with the aid of a digital microscope (BZ-8000, Keyence). High-resolution images were used to trace the cavity areas. Areas identified in individual sections were measured with the use of an image analysis software (ImageJ). The areas of the cavities were measured on 6 serial axial sections with a section-to-section interval of $2 \mathrm{~mm}$. These six measurements were added and averaged to produce the relative quantification data for each animal.

\subsection{Protein Isolation}

Fifty micrograms of spinal cord at L4/5 from each animal (injury, $n=4$; injury + immobilization, $n=4$ ) was homogenized in $1000 \mu \mathrm{L}$ of ice-cold lysis buffer (137 mM NaCl, 1\% NP40, $20 \mathrm{mM}$ Tris-HCl [pH, 8.0], and a protease inhibitor (Halt Protease Inhibitor Cocktail, Thermo Fisher Scientific Inc., Kanagawa, Japan) using a mechanical homogenizer. Spinal cord homogenates were centrifuged at $1500 \times g$ for 15 min at $4^{\circ} \mathrm{C}$. The resulting supernatant was divided into several portions and frozen at $-80^{\circ} \mathrm{C}$.

\subsection{Enzyme-Linked Immunosorbent Assay (ELISA)}

For measurement of GDNF protein levels, spinal cord samples (laminectomy, $n=2$; injury, $n=4$; injury + immobilization, $n=4$ ) were examined by ELISA with acid treatment procedure (GDNF kit, Novus Biologicals, CO). ELISA was performed twice for each sample.

\subsection{Statistical Analyses}

Analysis of variance was used to characterize group differences. In the case of a significant $\mathrm{F}$ ratio by a one-way analysis of variance, a Tukey's post-hoc test was performed. In all cases, the level of significance was set at P < 0.05 or $\mathrm{P}<0.01$. Data are presented as the mean \pm standard deviation, unless otherwise indicated.

\section{Results}

\subsection{Decrease in GDNF Level at L4/5 Spinal Cord Segment}

We previously reported that the injury + immobilization group had lower GDNF levels in muscles compared to the injury group. In this study, intramyocellular GDNF proteins were significantly decreased in the injury and injury + immobilization groups at 3 weeks postintervention (Figures 1(A)-(C)).

GDNF content at the L4/5 spinal cord segment was measured using ELISA. The injury + immobilization 

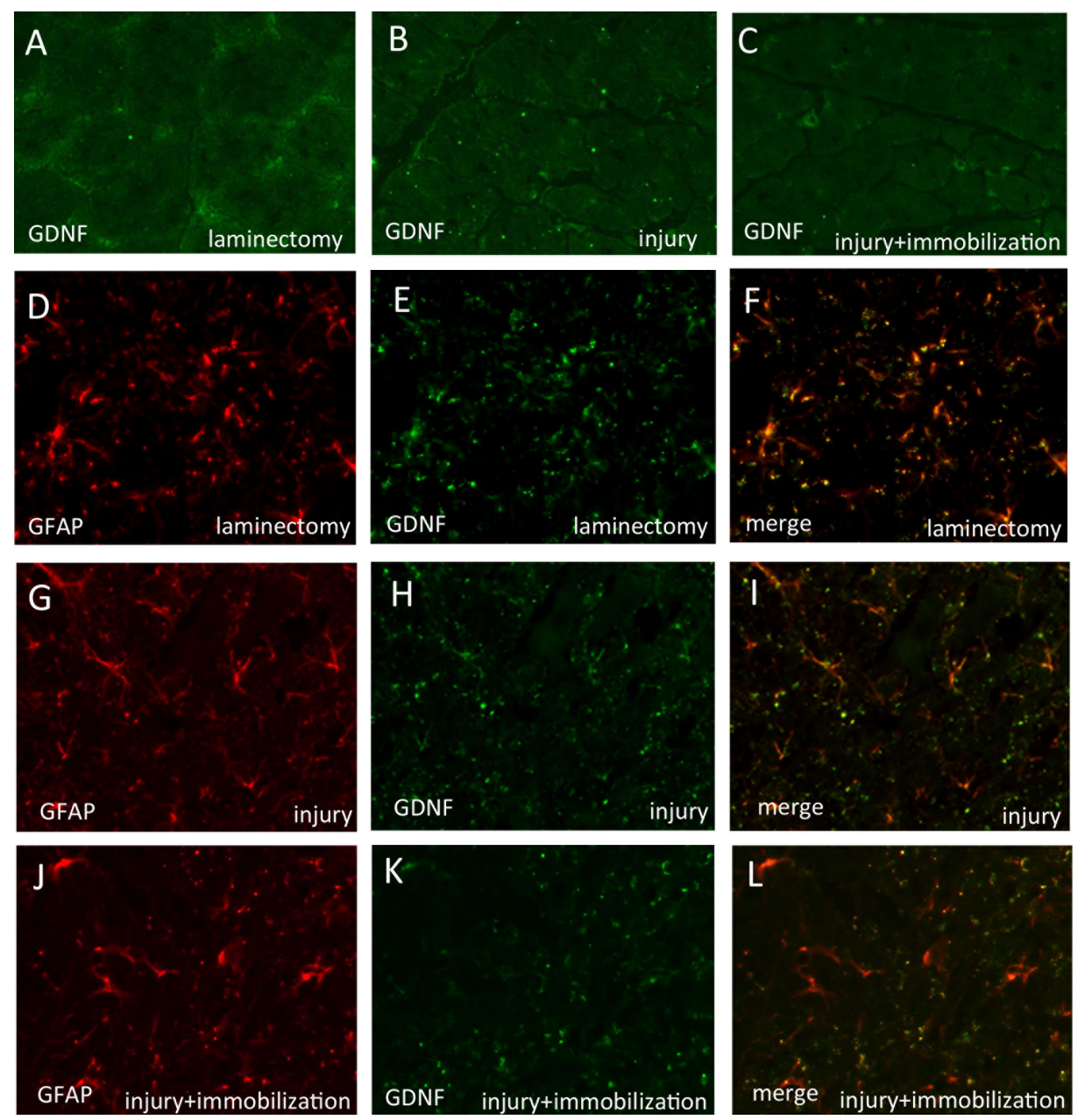

Figure 1. Immunohistochemical analysis for GDNF and GFAP proteins in the gastrocnemius muscle (A)-(C), and in the L4/5 segment of the spinal cord (D)-(L) at 3 weeks postintervention. (A) (D)-(F) laminectomy group, (B) (G)-(I) injury group, (C) (J)-(L) injury + immobilization group; GDNF (A)-(C) (E), (H), (K), GFAP (D), (G), (J), merge (F), (I), (L). Original magnification: $200 \times$.

group exhibited a significant decrease in GDNF proteins at 3 weeks postintervention compared to the injury and laminectomy group (Figure 2(A)). L4/5 spinal cord segments were not immunopositive for GDNF in injury + immobilization group, but slightly immunopositive in injury group (Figures $1(\mathrm{D})-(\mathrm{L})$ ) compared to the laminectomy group.

\section{2. $\alpha$-MN Rescue by GDNF}

We administered the recombinant GDNF proteins into the gastrocnemius muscle of rats in the injury + immobilization group. We measured the wet weight of muscle as the degree of disuse muscle atrophy. The average of wet weight of gastrocnemius muscle in PBS group $(n=3)$ and GDNF injection group $(n=4)$ was $1.13 \pm 0.35$ and $1.16 \pm 0.25$ respectively. The wet weight of gastrocnemius muscle in GDNF injection group did not differ from that of the PBS group at 3 weeks postintervention. The number of L4/5 $\alpha$-MNs was $3.0 \pm 1.41$ in the control PBS injection group and $6.25 \pm 1.25$ in the GDNF injection group (Figure 3(A), Figure 3(B)). $\alpha$-MN degeneration was partially rescued by exogenous GDNF proteins.

The mean volume of these cavities around the lesions did not differ significantly between the injury and injury + immobilization group (Figure 2(B)) or the PBS injection group and GDNF injection group at 3 weeks postintervention (Figure 3(C), Figure 3(D)). 


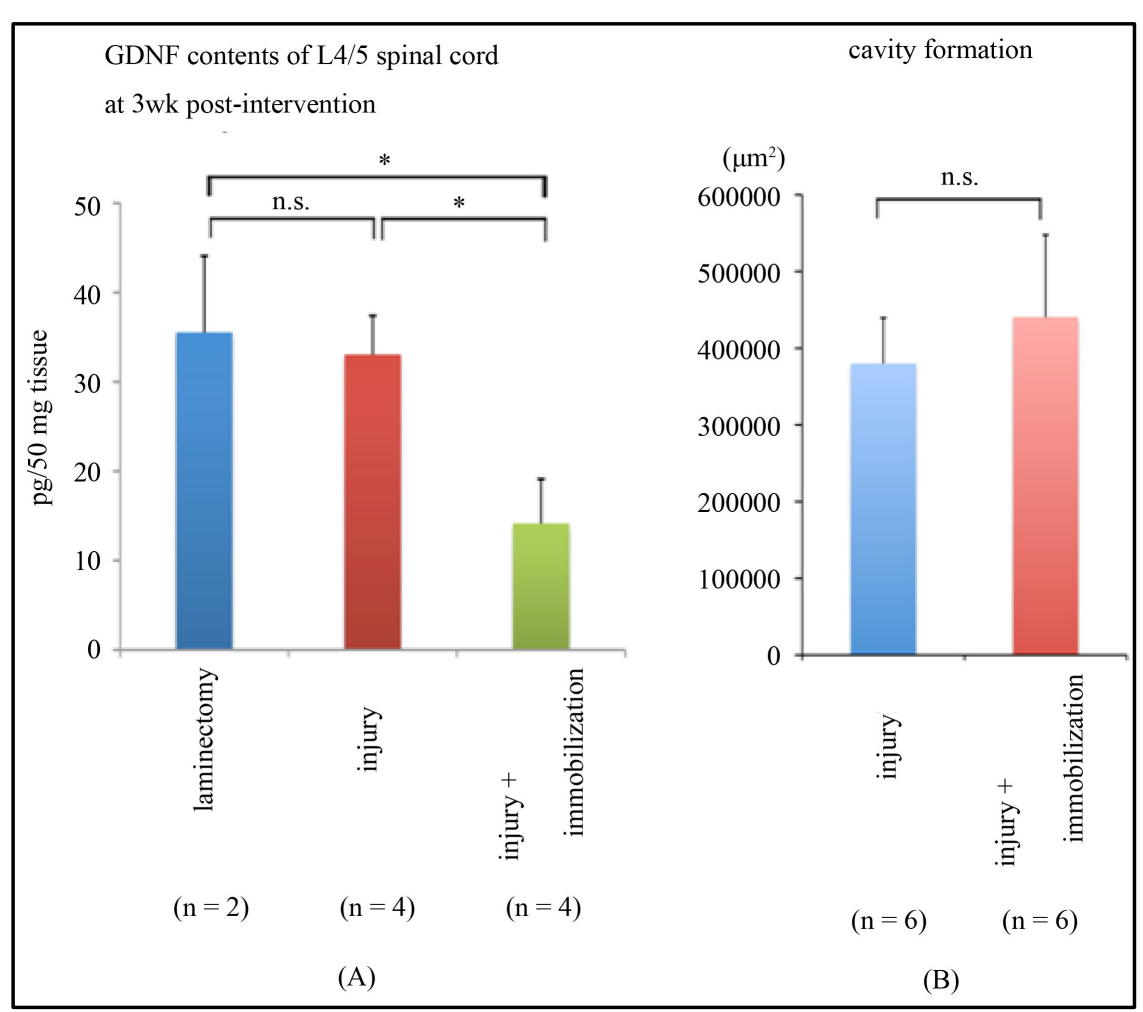

Figure 2. (A) ELISA for GDNF content of L4/5 spinal cord at 3 weeks postintervention; (B) Histogram showing the mean $( \pm \mathrm{SD})$ cavity volume in the injury and injury + immobilization groups ( ${ }^{*} \mathrm{P}<0.05$, n.s.; not significant).

\section{Discussion}

Widenfalk et al. created the thoracic contusion model, using the NYU impactor in the same way as our contusion model and at the same thoracic level [23]. They presented the expression of GFR $\alpha 1$ and RET in lumbar MNs of normal rats or rats with thoracic spinal cord injury. They also revealed no expression of GDNF in the lumbar segment of either normal or injured spinal cord. Their findings show that lumbar GDNF proteins are transported in both anterograde and retrograde directions from the spinal cord or muscle.

In this study, we have demonstrated that disuse muscle atrophy within the context of spinal cord injury exacerbates the reduction in GDNF proteins in caudal regions remote from the injury. The injury + immobilization group had lower GDNF levels in muscles and L4/5 spinal cord compared to the injury group [11]. While the injury + immobilization group had no significant difference from the injury group in the extent of spinal lesions. These data indicate that the decrease of GDNF in atrophic muscle cause the decrease in L4/5 spinal cord. Then we investigated whether the administration of recombinant GDNF proteins into the gastrocnemius muscle in the injury + immobilization group rescued $\alpha$-MN degeneration.

Figure 3 present that $\alpha$-MN degeneration was partially rescued by exogenous GDNF proteins into disuse muscle. These findings suggest that the depletion of GDNF protein by muscle atrophy causes a reduction in GDNF proteins at the L4/5 spinal cord segment. It is possible that in addition to exerting an effect through retrograde transport, GDNF affected $\alpha$-MN survival by being transported through the systemic circulation as well.

In this study, the mean volume of cavities around the lesion did not differ significantly between the injury and injury + immobilization group (Figure 2(B)). It was suggested that disuse muscle atrophy did not alter the extent of lesion. The injection of GDNF proteins into the gastrocnemius muscle partially rescued $\alpha$-MN degeneration in the L4/5 spinal cord segment. While the cavity volumes did not differ significantly between the PBS and GDNF injection group (Figure 3(C)). GDNF cause cell survival in the contused spinal cord tissues [24] [25]. Therefore the timing or volumes of GDNF injection may be late or insufficient respectively to prevent secondary effect of spinal cord injury. 


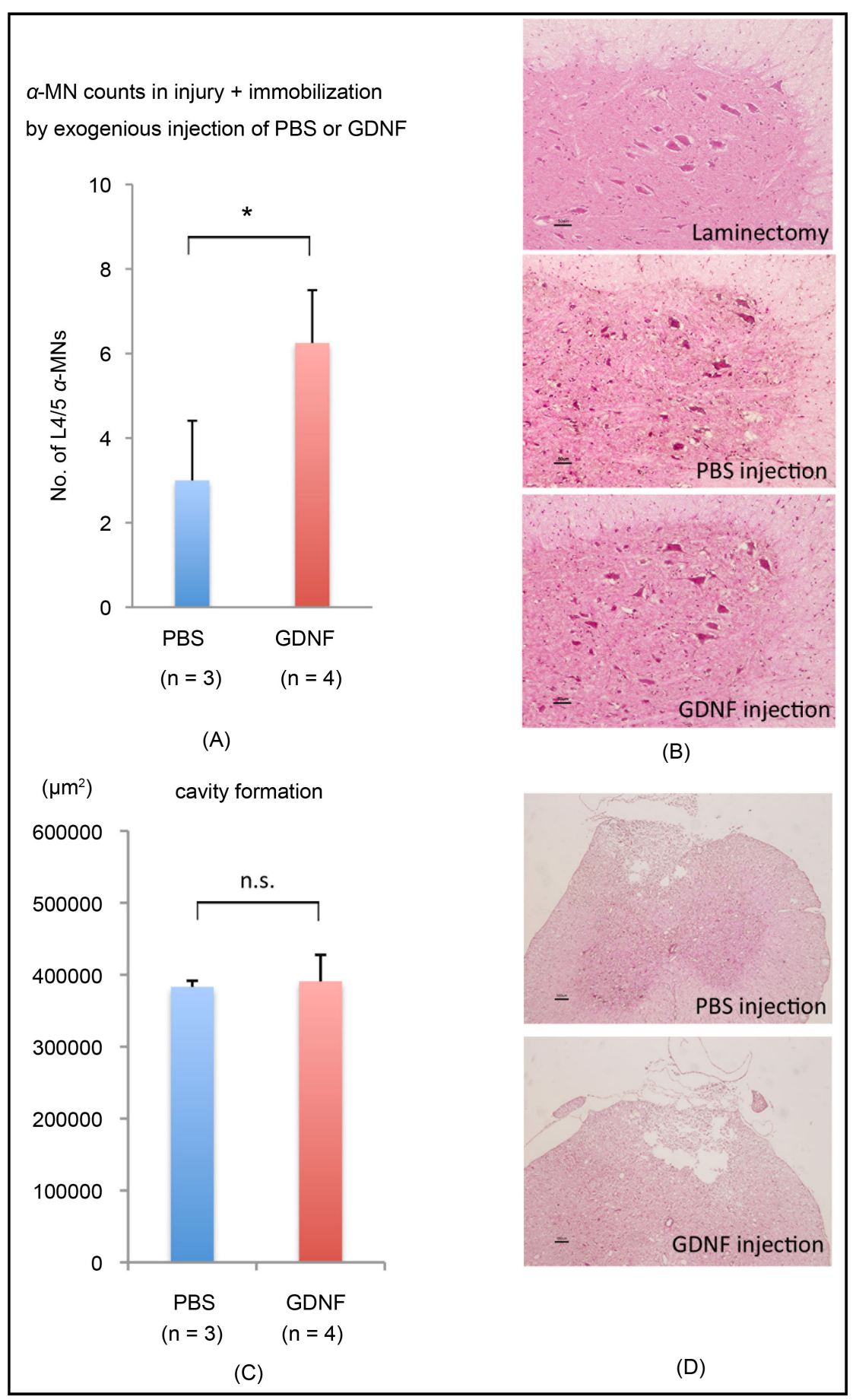

Figure 3. (A) $\alpha$-MN counts in the injury + immobilization group by exogenous injection of recombinant rat GDNF or PBS into the gastrocnemius muscle; (B) HE staining of ventral horn at L4/5 segment in the Laminectomy, PBS injection and GDNF injection group. Black bar $=50 \mu \mathrm{m}$; $(\mathrm{C})$ Histogram showing the mean $( \pm \mathrm{SD})$ cavity volume in the PBS and GDNF injection groups; (D) HE staining of cavity lesions around epicenter. Black bar $=100 \mu \mathrm{m}$ ass screws; (B) C2 pedicle screws.

\section{Conclusion}

Our findings suggest that the depletion of GDNF protein by muscle atrophy exacerbates MN degeneration in 
caudal regions remote from the injury.

\section{Acknowledgements}

This study was supported by grants from the Funding Program for World-Leading. Innovative R \& D on Science and Technology and Global COE Program from the Japanese Ministry of Education, Culture, Sports, Science, and Technology. We thank Y. Takahashi for secretarial aid.

\section{Conflict of Interest Declaration}

The authors declare no conflicts of interest with respect to the authorship or publication of this article.

\section{References}

[1] Bohn, M.C. (2004) Motoneurons Crave Glial Cell Line-Derived Neurotrophic Factor. Experimental Neurology, 190, 263-275. http://dx.doi.org/10.1016/j.expneurol.2004.08.012

[2] Airaksinen, M.S. and Saarma, M. (2002) The GDNF Family: Signalling, Biological Functions and Therapeutic Value. Nature Reviews Neuroscience, 3, 383-394. http://dx.doi.org/10.1038/nrn812

[3] Cary, G.A. and La Spada, A.R. (2008) Androgen Receptor Function in Motor Neuron Survival and Degeneration. Physical Medicine and Rehabilitation Clinics of North America, 19, 479-494. http://dx.doi.org/10.1016/j.pmr.2008.03.002

[4] Kablar, B. and Rudnicki, M.A. (1999) Development in the Absence of Skeletal Muscle Results in the Sequential Ablation of Motor Neurons from the Spinal Cord to the Brain. Developmental Biology, 208, 93-109. http://dx.doi.org/10.1006/dbio.1998.9184

[5] Korsching, S. (1993) The Neurotrophic Factor Concept: A Reexamination. The Journal of Neuroscience, 13, 27392748.

[6] Booth, F.W. (1982) Effect of Limb Immobilization on Skeletal Muscle. Journal of Applied Physiology: Respiratory, Environmental and Exercise Physiology, 52, 1113-1118.

[7] Glover, E.I., Phillips, S.M., Oates, B.R., Tang, J.E., Tarnopolsky, M.A., Selby, A., Smith, K. and Rennie, M.J. (2008) Immobilization Induces Anabolic Resistance in Human Myofibrillar Protein Synthesis with Low and High Dose Amino Acid Infusion. The Journal of Physiology, 586, 6049-6061. http://dx.doi.org/10.1113/jphysiol.2008.160333

[8] Murton, A.J. and Greenhaff, P.L. (2009) Muscle Atrophy in Immobilization and Senescence in Humans. Current Opinion in Neurology, 22, 500-505. http://dx.doi.org/10.1097/WCO.0b013e32832f15e1

[9] Gallego, R., Kuno, M., Núñez, R. and Snider, W.D. (1979) Dependence of Motoneurone Properties on the Length of Immobilized Muscle. The Journal of Physiology, 291, 179-189.

[10] Gomes, A.R., Cornachione, A., Salvini, T.F. and Mattiello-Sverzut, A.C. (2007) Morphological Effects of Two Protocols of Passive Stretch over the Immobilized Rat Soleus Muscle. Journal of Anatomy, 210, 328-335. http://dx.doi.org/10.1111/j.1469-7580.2007.00697.x

[11] Ohnishi, Y., Iwatsuki, K., Shinzawa, K., Nakai, Y., Ishihara, M. and Yoshimine, T. (2012) Disuse Muscle Atrophy Exacerbates Motor Neuronal Degeneration Caudal to the Site of Spinal Cord Injury. NeuroReport, 23, 157-161. http://dx.doi.org/10.1097/WNR.0b013e32834f4048

[12] Côté, M.P., Azzam, G.A., Lemay, M.A., Zhukareva, V. and Houlé, J.D. (2011) Activity-Dependent Increase in Neurotrophic Factors Is Associated with an Enhanced Modulation of Spinal Reflexes after Spinal Cord Injury. Journal of Neurotrauma, 28, 299-309. http://dx.doi.org/10.1089/neu.2010.1594

[13] Wehrwein, E.A., Roskelley, E.M. and Spitsbergen, J.M. (2002) GDNF Is Regulated in an Activity-Dependent Manner in Rat Skeletal Muscle. Muscle \& Nerve, 26, 206-211. http://dx.doi.org/10.1002/mus.10179

[14] Aoki, M., Kishima, H., Yoshimura, K., Ishihara, M., Ueno, M., Hata, K., Yamashita, T., Iwatsuki, K. and Yoshimine, T. (2010) Limited Functional Recovery in Rats with Complete Spinal Cord Injury after Transplantation of WholeLayer Olfactory Mucosa: Laboratory Investigation. Journal of Neurosurgery: Spine, 12, 122-130. http://dx.doi.org/10.3171/2009.9.SPINE09233

[15] Ide, C., Nakai, Y., Nakano, N., Seo, T.B., Yamada, Y., Endo, K., Noda, T., Saito, F., Suzuki, Y., Fukushima, M. and Nakatani, T. (2010) Bone Marrow Stromal Cell Transplantation for Treatment of Sub-Acute Spinal Cord Injury in the Rat. Brain Research, 1332, 32-47. http://dx.doi.org/10.1016/j.brainres.2010.03.043

[16] Iwatsuki, K., Yoshimine, T., Kishima, H., Aoki, M., Yoshimura, K., Ishihara, M., Ohnishi, Y. and Lima, C. (2008) Transplantation of Olfactory Mucosa Following Spinal Cord Injury Promotes Recovery in Rats. NeuroReport, 19, 1249-1252. http://dx.doi.org/10.1097/WNR.0b013e328305b70b 
[17] Gruner, J.A. (1992) A Monitored Contusion Model of Spinal Cord Injury in the Rat. Journal of Neurotrauma, 9, 123128. http://dx.doi.org/10.1089/neu.1992.9.123

[18] Metz, G.A., Curt, A., van de Meent, H., Klusman, I., Schwab, M.E. and Dietz, V. (2000) Validation of the WeightDrop Contusion Model in Rats: A Comparative Study of Human Spinal Cord Injury. Journal of Neurotrauma, 17, 1-17. http://dx.doi.org/10.1089/neu.2000.17.1

[19] Young, W. (2002) Spinal Cord Contusion Models. Progress in Brain Research, 137, 231-255. http://dx.doi.org/10.1016/S0079-6123(02)37019-5

[20] Ichiyama, R.M., Broman, J., Edgerton, V.R. and Havton, L.A. (2006) Ultrastructural Synaptic Features Differ between Alpha- and Gamma-Motoneurons Innervating the Tibialis Anterior Muscle in the Rat. Journal of Comparative Neurology, 499, 306-315. http://dx.doi.org/10.1002/cne.21110

[21] Ishihara, A., Ohira, Y., Tanaka, M., Nishikawa, W., Ishioka, N., Higashibata, A., Izumi, R., Shimazu, T. and Ibata, Y. (2001) Cell Body Size and Succinate Dehydrogenase Activity of Spinal Motoneurons Innervating the Soleus Muscle in Mice, Rats, and Cats. Neurochemical Research, 26, 1301-1304. http://dx.doi.org/10.1023/A:1014245417017

[22] Roland, R.R., Matsumoto, A., Zhong, H., Ishihara, A. and Edgerton, V.R. (2007) Rat $\alpha$ - and $\gamma$-Motoneuron Soma Size and Succinate Dehydrogenase Activity Are Independent of Neuromuscular Activity Level. Muscle \& Nerve, 36, 234241. http://dx.doi.org/10.1002/mus.20810

[23] Widenfalk, J., Lundströmer, K., Jubran, M., Brene, S. and Olson, L. (2001) Neurotrophic Factors and Receptors in the Immature and Adult Spinal Cord after Mechanical Injury or Kainic Acid. The Journal of Neuroscience, 21, 3457-3475.

[24] Iannotti, C., Zhang, Y.P., Shields, C.B., Han, Y., Burke, D.A. and Xu, X.M. (2004) A Neuroprotective Role of Glial Cell Line-Derived Neurotrophic Factor Following Moderate Spinal Cord Contusion Injury. Experimental Neurology, 189, 317-332. http://dx.doi.org/10.1016/j.expneurol.2004.05.033

[25] Tai, M.H., Cheng, H., Wu, J.P., Liu, Y.L., Lin, P.R., Kuo, J.S., Tseng, C.J. and Tzeng, S.F. (2003) Gene Transfer of Glial Cell Line-Derived Neurotrophic Factor Promotes Functional Recovery Following Spinal Cord Contusion. Experimental Neurology, 183, 508-515. http://dx.doi.org/10.1016/S0014-4886(03)00130-4 
Scientific Research Publishing (SCIRP) is one of the largest Open Access journal publishers. It is currently publishing more than 200 open access, online, peer-reviewed journals covering a wide range of academic disciplines. SCIRP serves the worldwide academic communities and contributes to the progress and application of science with its publication.

Other selected journals from SCIRP are listed as below. Submit your manuscript to us via either submit@scirp.org or Online Submission Portal.
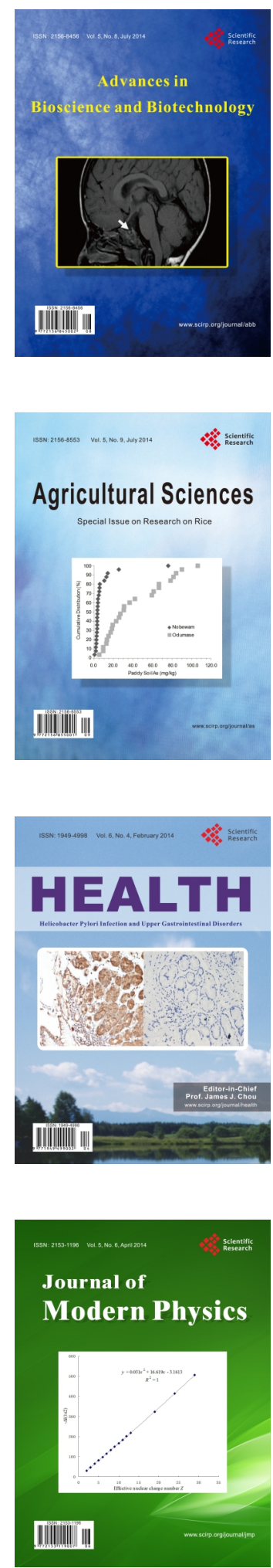
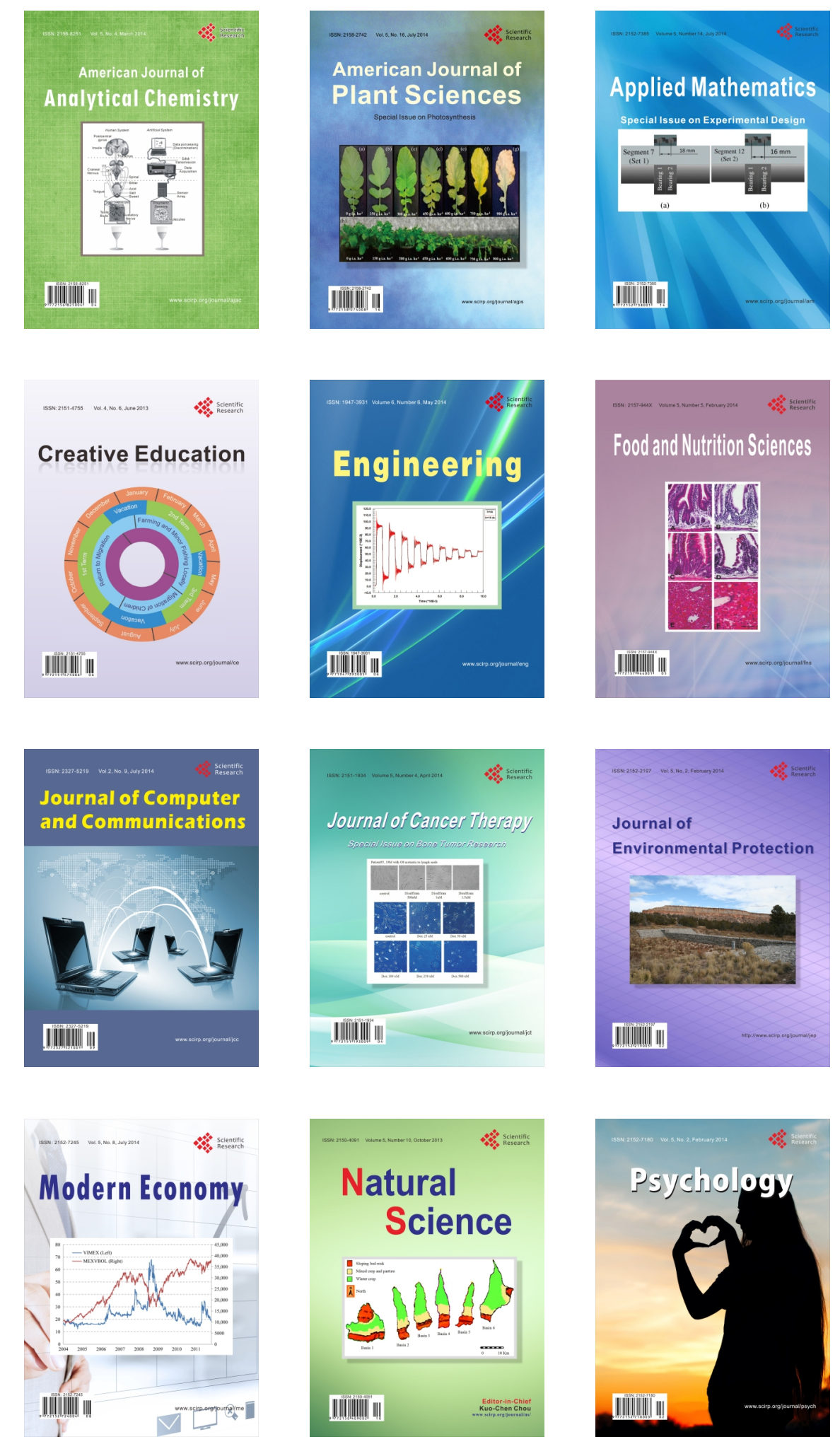